\title{
European Molecular Biology Laboratory
}

On 10 May 1973 at CERN, Geneva, an Agreement to create the European Molecular Biology Laboratory at Heidelberg was signed. The Laboratory is a special project of the intergovernmental organization, the European Molecular Biology Conference.

The Agreement is modelled on the CERN Convention. The Director-General designate is J. C. Kendrew, who received the Nobel Prize in 1962 for his work on the structure of proteins.

Member States have committed themselves for seven years when the non-recurrent expenditure is estimated as 11 million accounting units (A. U.) at 1972 prices (1 A. U. equals roughly $\$ 1$, including that on out-stations at DESY in Hamburg and the Laue-Langevin Laboratory in Grenoble. Operating costs will rise to 4.2 million $\mathrm{A}$. $\mathrm{U}$. per year.

In addition to providing the site, the Federal Republic of Germany is making a gift of DM 12 million which reduces the contributions to nonrecurrent expenditure over the first seven years to 7.7 million A. U. Moreover, Heidelberg has offered significant help, particularly with temporary accommodation, to facilitate the rapid start of the project.

\section{UNISIST Newsletter}

The first issue of the new UNISIST Newsletter is now available. It provides information on all aspects of the development and implementation of the world-wide programme of scientific and technical information and related activities. Details of English and French versions may be obtained from :

Division of Scientific and Technological Information and Documentation, Unesco, 7, place de Fontenoy, F-75700 Paris, France.

\section{Society News}

\section{Associate Members}

The following organizations have decided to join EPS as Associate Members :

Max-Planck-Institut für Festkörperforschung,

Stuttgart, Fed. Rep. of Germany ; Siemens Aktiengesellschaft, Berlin and Munich, Fed. Rep. of Germany; Swiss Institute for Nuclear Research (SIN), Villigen, Switzerland

\section{Atomic Spectroscopy}

At the Fifth Annual Conference on Atomic Spectroscopy in Lund from 10-13 July 1973, there will be an assembly of members of the Atomic Spectroscopy Section (EGAS) of the Atomic Physics Division at which three new board members will be elected.

\section{Europhysics Journals}

The Institute of Physics intends to publish 18 issues of Journal of
Physics A : Mathematical, Nuclear and General in 1974, of which approximately half will be devoted to nuclear physics. Every effort will be made to publish Letters as rapidly as possible in special sections near the front of the journal. W.D. Hamilton of the University of Sussex has been invited to join the Editorial Board as a Deputy Editor to oversee the nuclear physics issues, and it is proposed to appoint further nuclear physicists in Britain and on the continent of Europe to the Editorial Board.
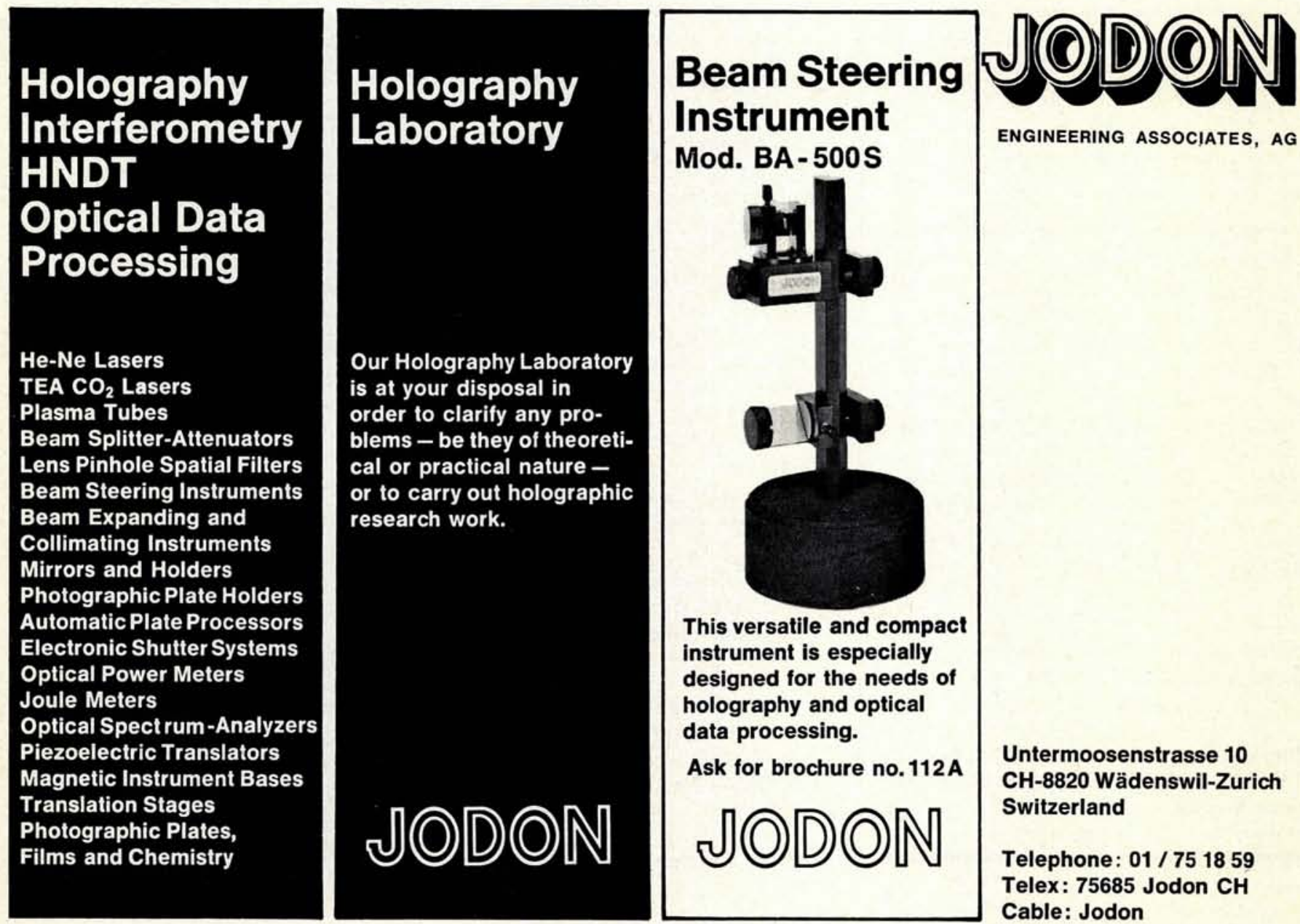

ENGINEERING ASSOCIATES, AG

Untermoosenstrasse 10 CH-8820 Wädenswil-Zurich Switzerland

Telephone: $01 / 751859$ Telex: 75685 Jodon $\mathbf{C H}$ Cable: Jodon 